\title{
2. MiFID II between European rule-making and national market surveillance: the case of high-frequency trading
}

Johannes Karremans and Magnus G. Schoeller

\subsection{INTRODUCTION}

In line with the spirit of the regulatory reforms initiated after the outbreak of the global financial crisis in 2008, the EU reviewed its 'Markets in Financial Instruments Directive' (MiFID). As this was an action coordinated at the international level, this initiative allows us to look into the theoretical propositions developed in our first research perspective, that is, the 'vertical perspective'. The revised legislative package, MiFID II, entered into force in January 2018 and consists for the most part in extending public oversight of those areas of the financial market that between the 1980s and 2000s mostly operated in the dark. More precisely, one of the key objectives of MiFID II was to introduce reporting obligations in market segments that until recently operated directly between buyers and sellers or on alternative trading venues (see Chapter 6 for two illustrative case studies).

The lack of public oversight in the pre-crisis era was related not only to the predominance of the neoliberal paradigm in the international political economy and financial markets, but also to an exponential growth in the number and complexity of financial instruments. Technological progress played an important role in this growth as it allowed for a significant increase in the speed and volume of simultaneous transactions. Public oversight was therefore not only discouraged by the idea that markets would best regulate themselves but also by the technical difficulty of bringing complex expanding markets under regulatory control.

In an effort to reform financial market regulation in Europe, MiFID II addressed this challenge as it introduced European legislation into an area 
of the financial markets in which technological innovation plays a defining role, namely high-frequency-trading (HFT) transactions. HFT is a specific form of 'algorithmic trading' that is distinguished by the speed and intensity with which transactions occur. Using algorithms and elaborate software, firms engaging in HFT trade financial assets at the milli- or even nanosecond level. As public oversight in this sphere requires the development of equally advanced software to track and store information about these transactions, the implementation of such public regulation is a costly and burdensome enterprise. This raises the political question of how such costs should be distributed, not only between public and private actors but also between the national and supranational levels.

In addition to addressing the technological challenge of regulating transactions happening in nanoseconds, MiFID II's rules on HFT also extended the reach of European legislation into an area in which different member states have different traditions of market surveillance. Particularly in the years following the eurozone crisis, member states increasingly started developing conflicting views on the regulation of finance, with HFT being one of the most heated issues. These conflicting views were strongly related to the role HFT played in their national economies. Being home to some of the main HFT traders, the Dutch government, for instance, was a strong advocate of limiting public regulation of HFT (The Economist 2013). Countries like Italy and France, by contrast, tended to be staunch proponents of strict HFT regulation (Financial Times 2013).

Among the many legislative provisions in MiFID II aimed at expanding public oversight, those on HFT constitute an ideal case study for discussing our questions of whether and how the recent reforms of financial regulation in Europe constitute a centralisation of rule-making. On the one hand, in fact, the rules seem to constitute an unambiguous case of centralising legislative power in EU financial regulation, as prior to MiFID II HFT had been entirely unregulated in the EU. On the other hand, however, and as our analysis will show, the new legislation also leaves considerable leeway for member states to implement it according to their views on HFT, particularly when it comes to market surveillance.

Based on our theoretical conjectures on the driving forces behind centralisation in the context of international agreements, in the following pages we seek to explain the emergence of the EU's regulation of HFT and to explore the challenges and consequences of its implementation. To do this, we rely on original evidence from legislative texts, European Parliament (EP) documents and debates, the European Commission's ${ }^{1}$ stakeholder consultation prior to proposing MiFID II, the guidelines and policy documents released by the European Securities and Markets Authority (ESMA), (financial) media reports and semi-structured elite interviews. Our analysis is divided into two parts, 
with the first part focusing on the emergence of HFT regulation in the EU and the second examining the challenges related to the implementation of the new rules.

With regard to the emergence of the EU's HFT regulation, we argue that the G20-led agenda on better regulation of financial markets and the rapid growth of financial technology (fintech) in conjunction with the financial crisis of 2008 opened a window of opportunity for the EU institutions to advance the centralisation of HFT regulation at the European level. Concerning the implementation of the new regulation, our argument is that it represents a centralisation of rule-making when it comes to defining the technical standards which firms and trading venues are required to adhere to when reporting on their activities. Regarding market surveillance, however, we argue that the new rules might very well lead to patterns of decentralisation. In particular, this second part of our argument relies on original interview material that shows how differently Dutch and Italian regulators view HFT and its implications.

\subsection{THE EMERGENCE OF HIGH-FREQUENCY-TRADING REGULATION IN THE EU}

MiFID II in general and its HFT rules in particular constitute an under-explored area of financial market research, especially in the political science literature. While lawyers and economists have provided extensive analyses regarding the content of the new provisions (e.g. Busch 2016; Busch and Ferrarini 2017; Ferrarini and Moloney 2012; Sheridan 2017), we still know very little about the political forces and dynamics that led to the unprecedented HFT regulation.

In terms of its content, the MiFID II rules on HFT are very much in line with the broader aim of increasing the transparency of financial markets. First, MiFID II provides a legal definition of HFT based on the specific technological infrastructure, system-determination and high message intraday rate of orders, quotes and cancellations. Second, HF traders are required to establish internal systems and controls according to technical standards specified by the ESMA. Third, they must notify the competent authorities of their activities, both in their home country and at the trading venue. Fourth, HFT firms need to provide detailed information about their algorithmic trading strategy, activities, and compliance and risk measures, either on a regular basis or ad hoc whenever the competent authority asks for it. Moreover, they are subject to reporting requirements regarding all executed and deleted orders. Fifth, MiFID II stipulates specific requirements for HF traders that pursue a market-making strategy, such as an obligation to provide liquidity on a continual and regular basis. Finally, trading venues are also required to have internal systems and controls to ensure that HFT does not lead to disorderly markets. These meas- 
ures include an 'order-to-trade' ratio, possible limitations of trading volumes and a 'flagging' system that allows venues to identify HF traders and their orders (see Busch 2016; Gomber and Nassauer 2014, p. 15f).

The Commission presented the legislative proposal for MiFID II on 20 October 2011 after having conducted an extensive review of the preceding MiFID I legislation, which included a large stakeholder consultation. However, as we will show below, much of the specific HFT legislation was introduced by the EP in the course of an ordinary legislative procedure. The legislative process was accompanied by an extensive impact assessment, related studies and yet another stakeholder consultation carried out by the EP (Ferrarini and Moloney 2012, p. 560). The EP adopted its amendments to the Commission's proposal in a first reading on 26 October 2012, and debates in the Council were held from February 2013. On 15 April 2014 the EP eventually adopted a compromise struck with the Council in trialogue negotiations, which was followed by the Council's decision on 13 May 2014, so that the final act could be signed on 15 May $2014 .{ }^{2}$ After the original starting date had been postponed by a year due to technical issues related to its implementation by financial firms, MiFID II finally entered into force on 3 January 2018.

The new EU regulation of HFT is clearly in line with the G20 goal of regulating and supervising all actors and practices that could jeopardise financial stability. Therefore, the G20 agenda kicked off in Pittsburgh in 2009 provided a legitimate background for the EU to advance its own regulation in this area. ${ }^{3}$ Indeed, there are at least four reasons for considering HFT a systemic risk factor. First, due to the large volume of orders in $\mathrm{HFT}^{4}$ there is a risk of overloading the system, leading to malfunctioning of the markets. Moreover, the fast placing and removing of orders may result in an instable order book and therefore lead to uncertainty for other market participants. Second, there is a risk of HFT amplifying volatility and therefore leading to over-reactions in the markets. Third, given that the contribution of HFT to capital formation is virtually insignificant and other market participants lack the same access to the order book, investors may switch to dark markets in order to avoid interaction with HF traders. Finally, due to its technological advantage regarding the speed and volume of transactions, HFT may be particularly well-suited to market manipulation or other abusive techniques (see Recital 62, MiFID II; Conac 2017, p. 472).

Although the EU regulation of HFT is thus perfectly in line with the G20 targets, it is not a direct response to the G20 agreement (Interview 1). Indeed, the terms 'algorithmic' and 'high-frequency trading' do not even appear in the Pittsburgh summit statement. Only at the G20 Seoul summit in November 2010 did leaders agree to mandate the International Organization of Securities Commissions (IOSCO) to develop recommendations on how to deal with "the risks posed to the financial markets by the latest technological developments". ${ }^{5}$ 
At that time, however, the European Commission had already started its review of MiFID (see above). Therefore, when the IOSCO's recommendations were endorsed at the G20 summit in Cannes in November 2011, the Commission had already concluded a large stakeholder consultation (Commission 2010) and officially proposed MiFID II, including its new provisions on HFT (Commission 2011). ${ }^{6}$

Following our first theoretical conjecture, we expect the decision-making rule (qualified majority voting vs. unanimity) to have an important impact on the final regulatory structure in the legislative outcome (H1.1 and H1.2, 'decision-making rule hypotheses'). To the extent that we can assume heterogeneous preferences regarding HFT regulation, this conjecture is corroborated by the case of MiFID II. While we cannot find evidence that member state governments, an EU institution or a significant share of stakeholders were completely against the regulation of HFT, preferences did diverge as to how the emerging practices should be regulated (see below, and also Interview 1). ${ }^{7}$ At the same time, no single member state or national veto player could have blocked the legislation on its own as it was shaped under co-decision. This gave the Commission, the EP and the supporting member state governments in the Council an opportunity to build a winning coalition in favour of centralising regulatory legislation on HFT at the EU level.

Within our first (vertical) research perspective, we also conjecture that de facto veto players - that is, powerful non-legislative actors such as interest associations, target groups and national supervisory authorities - can foster centralisation or decentralisation ( $\mathrm{H} 2$, 'de facto veto player hypothesis'). While this regards primarily the implementation of regulatory legislation at the national level (see below), powerful interest groups may also exert influence in the early phases of the decision-making process. As a matter of fact, stakeholders were consulted early and multiple times in the making of MiFID II. Not only did the Commission launch a major stakeholder consultation, but the Committee of European Securities Regulators (CESR), predecessor of the European Securities and Markets Authority (ESMA), and the EP also consulted the industry (Ferrarini and Moloney 2012, pp. 559f). This may have prevented more radical HFT regulatory proposals such as an introduction of minimum holding periods for orders or an obligation to provide constant liquidity to the markets. However, although the market response to the Commission may have been hostile in some respects (see Ferrarini and Moloney 2012, p. 584), most stakeholders did not oppose the regulation itself or its centralisation. On the contrary, they largely recognised the need to regulate HFT and supported individual provisions such as the requirement for HFT firms and trade venues to put in place specific risk controls and for co-location facilities to be offered on a non-discriminatory basis. ${ }^{8}$ 
In the theory chapter, we furthermore expected centralisation at the EU level to be more likely if the proposed legislation is compatible with that in large member states (H3, 'power/adjustment costs hypothesis'). Indeed, France and Germany ${ }^{9}$ already introduced national regulations in 2012 and 2013 respectively. The national legislation in these two large member states therefore predates EU legislation. In particular, the French regulatory regime is restrictive with regard to HFT, as the French regulatory authority (AMF) holds a critical view of HFT. In 2015, the AMF sanction commission decided on a $€ 5$ million sanction on high-frequency traders. This decision was interpreted as a de facto ban on HFT in France, given that the usual behaviour of high-frequency traders was judged to be a violation of French law (Conac 2017, pp. 473, 484f). Indeed, as an EU official explained, the French pushed HFT legislation "because they were concerned that this high-frequency trading was a way of manipulating the markets. So they were concerned that these people needed to have clear rules on transparency, on governance, to ensure that they would not disturb the markets too much" (Interview 1).

In Germany, by contrast, the national law on HFT anticipated the main features of MiFID II. For instance, the definition of HFT in MiFID II, Art. 4(40) mirrors the German definition and both laws require HF traders to notify their competent authorities, introduce internal systems and controls, and flag orders generated by algorithmic trading (see Conac 2017, p. 473; Sheridan 2017, p. 422). According to our interviews, it is indeed plausible that this congruence between the German and EU legislation is not a mere coincidence but is causally linked: "Before coming forward with legislative proposals there are some member states that are consulted. And those that have pre-existing legislation are probably the ones the Commission is speaking to most actively" (Interview 1).

Moreover, we conjectured in our theory chapter that in the absence of powerful veto players the Commission may use an international agreement to increase its institutional power by centralising regulation at the European level ( $H 5$, 'institutional empowerment hypothesis'). The evidence we find partly confirms this hypothesis but at the same time draws a more differentiated picture. It is true that MiFID II, and therefore also HFT regulation, stands in the broader context of the G20 targets set in Pittsburgh (Gomber and Nassauer 2014, p. 6; Kennedy 2017, p. 3; Moloney 2012, p. 328). However, there is no mention of HFT in the G20 summit document and neither does the Commission refer to the G20 in direct connection with HFT. Hence, we argue that the window of opportunity used by the Commission to introduce its HFT regulation was not only opened from the outside by the G20 agenda ${ }^{10}$ but also from the inside by the combination of the rapid and unpredictable rise of fintech and the financial crisis of 2008 (see Chapters 6 and 7). Already in its public consultation on the MiFID review in December 2010, the Commission 
made it clear that in its view HFT could pose a threat to the orderly functioning of markets and should therefore be regulated (Commission 2010, p. 15). In its official legislative proposal, the Commission explicitly mentions the emergence of HFT as one of the reasons for the initiative (Commission 2011, pp. $2,177 \mathrm{f})$. In addition, the relevant recital in the final directive relates the regulation of HFT to the sudden growth of fintech:

Technical advances have enabled high-frequency trading and an evolution of business models. [...] Yet that trading technology also gives rise to a number of potential risks [...]. It is appropriate to subject high-frequency algorithmic trading techniques $[\ldots]$ to particular regulatory scrutiny. ${ }^{11}$

The necessary political salience and legitimacy of HFT regulation was supplied by the financial crisis. Although the Commission did not claim a direct causal link between HFT and the crisis, it brought the issues 'crisis', 'consumer (investor) protection' and the 'rise of fintech' into close semantic connection. Thus, in its legislative proposal the Commission argued that

the financial crisis has exposed weaknesses in the regulation of instruments other than shares, traded mostly between professional investors. Previously held assumptions that minimal transparency, oversight and investor protection in relation to this trading is more conducive to market efficiency no longer hold. Finally, rapid innovation and growing complexity in financial instruments underline the importance of up-to-date, high levels of investor protection. (Commission 2011, p. 2)

Hence, as opposed to our conjecture, it was not only an international agreement but also internal developments that provided the Commission with the opportunity to foster the centralisation of HFT regulation. As an EU official put it:

Some of the proposals that came out after the crisis were led by the international agenda. But in fact the international agenda was also influenced by what was happening in Europe. [...] So you cannot say that the European agenda has been completely driven by the G20, because the European agenda has also influenced the G20 agenda [...]. Because this was in fact something that was made as a response to the crisis [...]. So you had the excuse of the crisis to come up with solutions for things that people already knew that MiFID I was not perfect at [...]. The structure of markets was not effective because you had platforms that were popping up outside the MiFID scope, where you had no supervision, no investor protection, no transparency. So the crisis was the excuse to sort out a number of bottlenecks that MiFID I had, that people were basically aware of. (Interview 1)

Finally, we conjectured that it is the Commission which advances regulatory centralisation at the EU level. However, a crucial finding of our analysis is that it was actually the EP which acted as 'policy entrepreneur' (Kingdon [1984] 
2003) by using the increased salience caused by the financial crisis and its role as formal co-decider to make HFT a central issue in the revised directive (see below; EP debate of 25 October 2012 $2^{12}$ ). This finding is in line with recent research suggesting that the EP strategically invests resources in salient policy issues in order to appear as the unique supporter of public interest (Meissner and McKenzie 2018). In fact, the Commission's original legislative proposal mentions HFT in the recitals but does not propose regulatory provisions specific to HFT (although many of the provisions on algorithmic trading would also apply to HFT). It was the EP which introduced HFT as a stand-alone subject of EU regulatory legislation. First, it introduced a specific definition of high-frequency trading (Amendment Art. 4(30a,b)), which was absent in the Commission's proposal. Although the final content of the definition mirrors the German legislation (Conac 2017, 473; Art. 4(40) MiFID II) rather than the EP's amendments, HFT thus became a separate regulatory item in MiFID II. Moreover, the EP introduced crucial provisions on specific storing requirements for HFT firms (Amendment Art. 17(2a) > Art. 17 (2) MiFID II), the testing of algorithms (Amendments Art. 51(3), 51(7ec) > Art. 48(6), 48(12g) MiFID II) and extra fees for market participants using HFT techniques (Amendment Art. 51(5a) > Art. 48(9) MiFID II). Although some of the amendments on HFT did not survive the legislative procedure - for example, the 500-millisecond holding period for orders - the EP succeeded in introducing HFT and making it one of the most salient issues in MiFID II (see the EP debate of 25 October 2012; ${ }^{13}$ Euractiv 2012 ${ }^{14}$ ).

Hence, the EU's HFT regulation came about as a reaction by the EU institutions to the rapid growth of fintech and the related systemic risks. The global financial crisis together with the G20 reaction kicked off at Pittsburgh in 2009 gave these measures a high level of saliency and legitimacy. They therefore opened a window of opportunity for the Commission to advance its own regulatory agenda. However, as this analysis shows, the entrepreneurial force behind the specific HFT regulation (going beyond the more general regulation of algorithmic trading) was the EP. Based on the Commission's legislative proposal, the EP introduced HFT as a stand-alone object of regulatory legislation and increased its salience as one of the most important parts of MiFID II. This allowed the EP, once again, to present itself as a promoter of the common good in the EU.

In the next section, we turn to the question of how the new legislation has been implemented in the member states. While the emergence of the new legislation is a clear case of centralisation, a closer look at its implementation draws a more differentiated picture. 


\subsection{THE IMPLEMENTATION OF HIGH-FREQUENCY-TRADING REGULATION IN THE EU}

As under MiFID II HFT is understood as a subset of algorithmic trading, the first rule of concern for firms dealing in HFT is the obligation to notify their activities both to the competent authority of the firm's home member state and to the authority of the member state of the trading venue at which the firm engages in algorithmic trading. ${ }^{15}$ While the national competent authorities provide firms and trading venues with the precise information about the format with which the order data is to be stored, the technical standards for firms and trading venues to implement systems for information storage are indicated in the Commission's delegated regulation of 2016, which also assigns to the ESMA the authority to clarify further specification of these standards. As delegated regulations apply directly and do not need to be transposed in national legislation, the technical standards defined by the Commission and the ESMA can directly be adopted by all firms operating in the EU's jurisdiction. Therefore, in terms of the technical standards to which firms must store information on their HFT activities, we can expect centralised patterns of implementation. In other words, we can expect the technical standards to which information on HFT transactions is stored to be the same across the whole EU.

With regard to how public authorities use and interpret the information stored by firms, however, we expect a different dynamic. Under MiFID II, in fact, member states have the responsibility to appoint a national authority that is responsible for carrying out market supervision. Furthermore, MiFID II does not contain further specifications as to how member states should carry out supervision, leaving them a considerable degree of autonomy (Conac 2017) and increasing the potential for decentralised patterns. As anticipated in the introduction, the regulation of HFT is a policy area in which different member states have different and contraposing interests. These contrapositions run largely parallel to different conceptions of how public authorities should intervene in financial markets, with the UK, Ireland and various northern European countries tending to favour financial innovation and light-touch regulation and continental European countries like France and Italy tending to favour a more restrictive regulation of the financial sector (Quaglia 2012). Consequently, as market supervision falls under the responsibility of national authorities, we expect that the veto power of member states increases, leading to a fragmentation of the criteria for interpreting certain market practices as abuses. In other words, we expect that the more autonomy member states have in carrying out market supervision, the more the information stored by firms is 
used and interpreted in different ways, leading de facto to a decentralised and fragmented implementation of the HFT provisions.

Our overall expectation, therefore, is that the implementation of HFT provisions features a mix of centralised and decentralised patterns. In the following pages, we will explore these patterns following our 'de facto veto player' (H2) and 'legal content' (H4.1 and H4.2) hypotheses presented in Chapter 1. More precisely, in the case of the implementation of technical standards, these hypotheses lead us to expect centralising patterns. The fact that these standards are defined by a delegated regulation bypasses the potential veto power of member states. In addition, the ESMA's role in providing further clarification of these standards presumably reduces the possibilities for diverse interpretations. In the case of market surveillance, by contrast, considering the lack of clear provisions as to how national authorities should carry out market supervision and the different views of member states on HFT, it is plausible to expect different national authorities to develop different criteria for defining and sanctioning market abuses. Our two hypotheses therefore lead us to expect that the autonomy left to the member states to implement market surveillance may lead to a decentralised regulatory structure.

To explore our conjectures, we rely on evidence coming from two main empirical sources, one focused on the European level, the other on the national level. The former consists in the information and policy documents available on the ESMA's website. The latter consists in interviews with members of national regulatory authorities coming from two opposing fronts regarding financial regulation (Quaglia 2012), namely the Italian Commissione Nazionale per la Societá e la Borsa (CONSOB - Italian financial markets authority) and the Dutch Authority for Financial Markets (AFM). The selection is based on the contraposing positions that Italy and the Netherlands have towards financial markets in general and HFT in particular. In other words, these interviews provide an assessment of the implementation of MiFID II from the perspective of regulators coming from two different hemispheres of European governance. As we shall see, one sees innovation in financial markets as a challenge and the other as an opportunity. By looking jointly at these three different sources, we are able to map both the forces pushing towards centralisation and - if any - the forces triggering decentralisation.

As anticipated, the implementation of MiFID II's provisions on HFT is a shared responsibility between private and public actors. The implementation of technical standards is mostly a burden to be carried by the former. The responsibilities of private actors are, in fact, already implicitly visible in various MiFID II articles in which, as already outlined in section 2.2, the rules with which firms dealing in HFT are expected to comply are stated. These obligations bring a considerable amount of cost to firms, as they are not only obliged to report their transactions to both their national authority and the 
national authority of the trading venue, but must store detailed information about the "nature of [their] algorithmic trading strategies, details of the trading parameters or limits to which the system is subject [and] the key compliance and risk controls that [they have] in place". ${ }^{16}$ The storage of such detailed information is burdensome, particularly when considering the technical standards which such information must meet.

While the national competent authorities provide firms and trading venues with precise information about the format in which the order data is to be stored, the Commission's delegated regulation of 25 April 2016 indicates the technical standards to which firms and trading venues must implement systems for information storage. These technical standards are also further clarified by a report and guidelines published by the ESMA (ESMA/2015/1464; ESMA/2016/1452). Broadly speaking, these technical standards oblige investment firms and trading venues to put in place a complex system storing information on transactions happening within fractions of seconds. This involves carrying out various tasks. The first consists in synchronising the respective business clocks, which is essential for identifying and distinguishing transactions happening in milli- or nanoseconds. The second task is to develop a complex system for storing information regarding the venue, trading date time, quantity, quantity currency, price, price currency, up-front payment, up-front payment currency and instrument details. ${ }^{17}$ In addition, when required, information should also be provided about how the transaction changed the market positions of the parties involved.

The most difficult technical standard to implement is arguably the storage of information on algorithmic transactions using micro- or millisecond granularity, depending on the case. This means storing the time of the transaction as the exact micro/millisecond in which it happened. While investment firms are burdened with the task of implementing highly sophisticated data storage systems, trading venues are required to monitor the trading activities being carried out on their platforms and to interfere in the transactions whenever there is a need to contain the growth and the pace of them. More specifically, trading venues are expected to reduce the number of unexecuted trades and to set certain minimum price movements for financial instruments.

Besides being technically challenging, these requirements burden private actors with considerable costs, in terms of both technical infrastructure and personnel (Kindermann et al. 2016). For this reason, there were serious concerns in the private sector about whether the kick-off date for MiFID II (3 January 2018) would "go well" (Kennedy 2017, 3), in the sense that it would not disrupt markets. So far, the kick-off of MiFID II has not caused disruption but it has started provoking significant changes in the markets, as since January 2018 dealing in HFT entails substantial investment in developing reporting systems. Therefore, the burdens on firms introduced by MiFID II are undoubt- 
edly producing winners and losers, with firms capable of sticking to the new requirements on the one hand, and firms for which the technical or personnel costs may become unbearable on the other (e.g. Financial Times 2018).

As was underscored by the national regulators we interviewed (Interviews 2, 3), the Commission's delegated regulation and the related report and guidelines published by the ESMA have an important function of harmonising the technical standards across the whole EU jurisdiction. The definition of technical standards in delegated regulations, in fact, ensures that they directly apply to all member states and do not need to be transposed into national legislation. Consequently, as there is almost no room for interpretation bias by national legislators, these technical standards are implemented consistently in all EU member states. The importance of delegated regulations for achieving homogeneous implementation was also acknowledged by our interviewees from the Dutch (Interview 2) and Italian (Interview 3) regulatory authorities, both when confronted with the question of whether EU legislation is helping their supervision of transnational markets and when asked about the extent to which such legislation establishes a common European framework. The two regulators not only both responded affirmatively to these questions but also underlined the positive impact of delegated regulations:

$[\ldots]$ we are happy with the idea that now not more and more directives are implemented, but regulation is coming that has a direct impact, so you do not have to implement that in the national legislation. And for us that is very helpful because you do not have to change your national law, and you do not have expectation differences. [...] You skip the national interpretation, implementation, therefore you have less interpretation issues. (Interview 2)

MiFID II/MiFIR and MADII/MAR introduced a comprehensive framework for the regulation, supervision and enforcement of risks related to algotrading and HFT and related market abuse practices. This goes from the introduction of a common definition of these trading techniques to the identification of specific obligations to be put in place by both investment firms and trading venues in terms of testing of the algorithm, IT controls, system capacity, flagging of orders, trading halts, etc, as well as the identification of specific market abuse practices linked to the use of HFT. In addition, it is noted that such requirements are mostly contained in delegated regulations issued by the European Commission, which are directly applicable in all EU member states and do not need to be transposed into national legislation. (Interview 3)

Both interviewees emphasised that the definition of technical standards through delegated regulations allows circumvention of the problem of national interpretation, thus reducing the de facto veto power of member states. Therefore, conforming with our 'de facto veto player' (H2) and 'legal content' (H4.1 and H4.2) hypotheses, the implementation of the technical standards constitutes the most centralising aspect of the HFT provisions contained in MiFID II. 
In contrast to the detailed guidelines on the technical standards that private actors must comply with, MiFID II's provisions regarding how national competent authorities should carry out their supervision tend to be rather opaque (Conac 2017). As a result, member states have considerable leeway in carrying out supervision in the way and intensity they deem appropriate, but also in imposing additional requirements on firms engaging in HFT (Kindermann et al. 2016). This leeway may tap into different traditions in dealing with financial markets and their latest developments. Some member states, like the Netherlands, have made innovation in financial markets one of their main national economic interests (The Economist 2013). This also impacts on the views that regulators have on innovation, and algorithmic trading in particular. When asked about whether and how technological innovation and HFT constitute a challenge for market surveillance, our interviewee from the Dutch AFM responded by underscoring his organisation's positive stance towards the innovations brought by traders:

Well, we are positive about traders. We think they are an essential part of the capital markets. And of course the trading behaviour, they put in a lot of orders, they do a lot of transactions - the high frequency traders - but on the other hand, they also give liquidity to the market. So to put it the other way round, if they are not in the market, it could be a quite empty market. [...] So we think that they are an important part of the capital markets and of course they should behave like everyone should behave. (Interview 2)

By contrast, when asked the same question, our interviewee from the Italian authority responded more negatively, highlighting the risks that HFT brings to the functioning and integrity of financial markets:

The significant weight and increasing importance of algotraders and HFTs in recent years have raised increasing attention by regulators as to the risks and potential drawbacks in terms of market quality. [...] The technological developments, such as algotrading and HFT, have brought to light new risks for the orderly functioning, transparency and integrity of capital markets. In particular, from a supervisory point of view, the use of HFT makes it harder to detect abuses and irregularities, given the high level of complexity of the algorithms used and of the strategies implemented. (Interview 3)

Contrary to the Dutch case, the Italian regulators seem to view innovations in financial markets as a real challenge for their regulatory systems. Consequently, market surveillance may develop in different ways in different member states, particularly when considering that MiFID II leaves national regulators with sufficient autonomy to develop such divergences.

When asked about whether there have been instances of divergent market surveillance in different member states since the entry into force of MiFID II, 
our interviewees from both the Dutch and Italian authorities answered that so far this has not been the case. However, both interviewees clearly perceived the heterogeneity of the different views of their counterparts in other member states and saw this as a challenge for uniform market surveillance. From the Dutch perspective, for instance, problems can arise in particular with southern European countries, as they are not part of the Euronext group ${ }^{18}$ and therefore have a highly different trading system:

We are part of the Euronext group - but a lot of other countries are not. They have a different trading system. Different issues can then arise. So what in one trading system can be acceptable is possibly not acceptable in another trading system. I'm not sure if it is possible to solve that because then you should say every country needs to have the same trading system and that's not what we want. (Interview 2)

When asked further about possible divergent views that different national authorities may have about HFT, our interviewee from the Dutch AFM again emphasised the different views that may emerge between countries that are part of Euronext and countries that are not, and that these differences run largely parallel to the differences between northern and southern European countries:

I think some of the southern European countries are more critical about it, but that's also because the trading system. [...] The trading system in Spain is very different to our trading system. It is also for Italy, but not for France because they're part of the Euronext system. [...] For us, I think our trading system, [...] especially Euronext, is quite familiar with the fact that HFT exists and we react on that. (Interview 2)

It is interesting to note from this quote how - in the configuration of divergent national interests - France is at times aligned with the Mediterranean countries (e.g. Wasserfallen and Lehner 2017) and at other times with the continental northern European countries (e.g. Quaglia 2012). The quote therefore seems to indicate that France is truly an in-between case, featuring characteristics of both the southern and the northern political economies.

On this same set of questions about possible divergent views among member states, our interviewee from CONSOB acknowledged the fact that such potential indeed exists, but stated that this threat has largely been tackled by the policy dialogues between national authorities and the ESMA (Interview 3). When asked about the kind of problems that could emerge from inconsistent application across member states, the CONSOB interviewee clearly pointed to regulatory arbitrage and to the risk of misapplication in some member states that may in turn lead to risk contagion. In addition, another potential problem indicated by the Italian regulator is the applicability of EU requirements to 
third-country firms using HFT. This problem may become particularly concrete once the United Kingdom has left the EU.

The different views on the supervision of financial markets are thus divided into two hemispheres of European governance, with the Dutch regulators being an example of the north-west and the Italian regulatory authority of the Mediterranean countries. The different perspectives on the challenges in the (mis)application of EU rules between Dutch and Italian authorities, therefore, is strongly linked to different views that national regulators have on the benign or malign characteristics and effects of HFT. As we have seen, when asked about the role that HFT plays in the spread of market abuses or irregularities, a clear contrast emerges between the Italian authorities pointing towards the relation between HFT and new risks to the integrity of capital markets and the Dutch authorities underlining instead the essential role that HFT traders play in the functioning of financial markets. These different national attitudes to HFT are likely to persist under MiFID II, as national authorities have the autonomy to investigate the legal conformity of the activities of the firms and venues operating in their jurisdictions (Conac 2017). Consequently, it is likely that in jurisdictions like the Netherlands the authorities will be more laissez faire and less likely to sanction certain misconducts, while in jurisdictions like Italy HFT may turn out to be more restricted. Therefore, for HFT market surveillance we find our 'de facto veto player' (H2) and 'legal content' (H4.1 and H4.2) hypotheses corroborated, as diverse stances on the risks related to HFT and the relative vagueness of EU provisions lead to decentralising patterns.

However, it is important to note the role that the ESMA has played in managing these differences so far. During the first years of implementation, ESMA provided an important forum for national regulators to compare their different views at the European level, which then led the ESMA to provide its set of responses to some of the controversies that emerged between national regulators (Interviews 2, 3). This is also in line with recent accounts of how the ESMA developed as a centralised European rule-maker in the post-crisis period (Spendzharova 2017). Since its foundation in 2008, in fact, the ESMA has fully exploited its role as the European standard setter in financial market regulation, while at the same time acting as a forum for national authorities to discuss their different points of view.

The decentralising effects of national diverging views on HFT may thus be tempered by the fact that effective investigation requires cross-border cooperation, and that the ESMA acts as a coordinator of such cooperation. The transnational nature of the markets in which HFT takes place means that in order to obtain a complete picture of a certain market activity information needs to be collected from different jurisdictions. Both the Dutch and Italian regulators, in fact, underlined that today there is a European system of mapping and tracking financial cross-border transactions in which every day each national 
authority sends a report on the activities in its national financial market to the ESMA, which in turn sends a report back with a complete European overview (Interviews 2, 3). In the long run, this cooperation might trigger a standardisation of market surveillance across the EU, which may be facilitated by the fact that the heads of the national authorities jointly constitute the ESMA's board of supervisors and are therefore responsible to the Commission for the correct functioning of financial markets under the framework of MiFID II. As the national regulators also underscored during our interviews, the frequent interactions between the ESMA and national regulators may very well lead towards generating a (centralised) European view on the surveillance of market malpractices.

\subsection{CONCLUSION}

MiFID II's provisions on HFT need to be seen as an extension of the G20 Pittsburgh agenda, with both the European Commission and the EP seeking to expand the scope of EU regulation to a type of trading that accounts for a large share of trades in European financial markets. Against a background of technological innovation and the lessons drawn from the financial crisis, the EU therefore has forcefully advanced the centralisation of financial regulation with regard to HFT. By drawing partly on existing legislation in Germany, the EU developed a common framework for the regulation of HFT in which firms are obliged to store and report information on their trades to the national competent authorities, which in turn are in charge of conducting market surveillance. Surprisingly, when it came to incorporating HFT regulation into MiFID II, it was the EP rather than the Commission which acted as policy entrepreneur centralising the regulation of HFT at the European level.

While the regulation of HFT constitutes a case of centralisation of rule-making, given that HFT was previously unregulated at the European level, regarding its implementation a more complex story needs to be told. As HFT relates to the economic interests of the member states in different ways, it also generates different views among public authorities on the extent to which it is a potential source of threat. As a result, we find that there are patterns of both centralisation and decentralisation in the implementation of EU regulation of HFT: a centralisation of rule-making, including the definition and implementation of technical standards; a decentralisation of the implementation of the new rules and surveillance of adherence to them. The former has been achieved through European legislation and delegated regulations that are directly applicable in all member states, and by placing the burden of implementation on firms dealing in HFT; the latter is triggered by national authorities' diverging views on HFT. 
From our analysis, it emerges that not only do different member states have diverging ways of looking at HFT but also that these differences may result in different ways of conducting market surveillance, which - in the regulators' view - may in turn lead to regulatory arbitrage or risk contagion. At the same time, however, we have also found that the ESMA is playing an important role in coordinating these differences by bringing together the diverging points of view of the national authorities and thus generating a common European view on market surveillance with regard to HFT. The extent to which this activity will suffice to prevent market surveillance within the EU being fragmented is still an open question.

\section{NOTES}

1. Hereafter, 'the Commission'.

2. See https://oeil.secure.europarl.europa.eu/oeil/popups/ficheprocedure.do ?reference $=2011 / 0298(C O D) \& l=e n$ (accessed 22 February 2019).

3. See Newman and Posner (2016) for the theoretical underpinning of this argument.

4. According to the ESMA (2014), the market share covered by HFT varies between $24 \%$ and $40 \%$, depending on the measurement approach.

5. The Seoul Summit Document, https://www.g20germany.de/Content/DE/ StatischeSeiten/Breg/G7G20/Anlagen/G20-seoul-gipfel-dokument-en__blob= publicationFile\&v=1.pdf (accessed 30 January 2019).

6. Hence, our hypotheses on the difference between vague and precise international agreements do not apply to the EU's HFT regulation.

7. See, e.g. the respective EP debates (http://www.europarl.europa.eu/sides/getDoc .do?pubRef=-//EP//TEXT+CRE+20121025+ITEM-017+DOC+XML+V0//EN\& language $=\mathrm{EN}$ accessed 30 January 2019), the contributions by national parliaments (http://www.connefof.europarl.europa.eu/connefof/app/exp/COM(2011)0656 accessed 30 January 2019) and the stakeholder responses to the Commission's consultation on the review of MiFID (Commission 2010). Even national authorities were in favour of regulating HFT at the European level. The Netherlands Authority for the Financial Markets (AFM), for instance, took a rather sceptical view regarding a strict regulation of HFT but it acknowledged that some degree of regulation was needed and, while taking into account the specific properties of the market structure in single countries, "given the international nature of the financial markets, this process should take place at not lower than European level. Unilateral national measures are useless and therefore undesirable".

8. A notable exception was BNP Paribas, which argued that "high-frequency trading should not be regulated at all". Moreover, one interviewee vaguely recalled fierce lobbying by the finance industry against HFT regulation, and explicitly referred us to the position of the Association for Financial Markets in Europe (AFME). However, when we examined their responses to the Commission's consultation, we found no evidence of fierce opposition, but general approval of the regulatory proposal as such and concerns or disagreement only in relation to single provisions. The interviewee also provided an explanation for this apparent contradiction: "I think probably they would prefer to kill it [the legislative proposal], but they understood that they would not be able to kill it, and [...] so they 
tried to soften. Whenever they find out that they cannot avoid having something, they simply try to soften it. And it does make sense, because basically then you would be in damage control mode. You will try to ensure that you will have at least something that makes sense and that you can work with."

9. France and Germany are the EU's most powerful member states in terms of economic and market size, population and voting weight in the Council (see, e.g. Krotz and Schild 2013; Schoeller 2018). One may speculate on the extent to which their powerful position in EU financial market regulation will increase with the exit of the United Kingdom and thus the City of London.

10. The G20 Pittsburgh agreement can instead be seen more as an enabling factor (or necessary condition) in that it legitimised the agenda of reform-minded actors in the EU to introduce stricter regulation of the financial markets (MiFID II and MiFIR), of which HFT regulation became a part (for the theoretical underpinning of this argument, see Newman and Posner 2016).

11. Directive 2014/65/EU of the European Parliament and of the Council of 15 May 2014 on markets in financial instruments and amending Directive 2002/92/EC and Directive 2011/61/EU Text with EEA relevance. link https:/eur-lex.europa.eu/ legal-content/EN/ALL/?uri=CELEX\%3A32014L0065 (accessed 8 April 2020).

12. http://www.europarl.europa.eu/sides/getDoc.do?pubRef=-//EP// $\mathrm{TEXT}+\mathrm{CRE}+20121025+\mathrm{ITEM}-017+\mathrm{DOC}+\mathrm{XML}+\mathrm{V} 0 / / \mathrm{EN} \&$ language $=\mathrm{EN}$ (accessed 30 January 2019).

13. http://www.europarl.europa.eu/sides/getDoc.do?pubRef=-//EP// $\mathrm{TEXT}+\mathrm{CRE}+20121025+\mathrm{ITEM}-017+\mathrm{DOC}+\mathrm{XML}+\mathrm{V} 0 / / \mathrm{EN} \&$ language $=\mathrm{EN}$ (accessed 30 January 2019).

14. https://www.euractiv.com/section/uk-europe/news/eu-lawmaker-turns-screw-on -ultra-fast-trading/ (accessed 6 February 2019).

15. Article 17, paragraph 2, MiFID II Directive.

16. Article 17, paragraph 2, MiFID II Directive.

17. ESMA, Guidelines on transaction reporting, order record keeping and clock synchronisation under MiFID II, ESMA/2016/1452, corrected on 7 August 2017.

18. Euronext is the largest stock exchange in continental Europe, and operates markets in Amsterdam, Brussels, London, Lisbon, Dublin, Oslo and Paris. It was founded in 2000 by a merger of the exchanges in Amsterdam, Paris and Brussels.

\section{BIBLIOGRAPHY}

Busch, Danny (2016) 'MiFID II: regulating high frequency trading, other forms of algorithmic trading and direct electronic market access,' Law and Financial Markets Review, 10:2, 72-82.

Busch, Danny and Guido Ferrarini (eds) (2017) Regulation of the EU Financial Markets: MiFIDII and MiFIR, Oxford: Oxford University Press.

Commission (2010) Public Consultation: Review of the Markets in Financial Instruments Directive (MiFID), 8 December 2010, Directorate General Internal Market and Services, Brussels.

Commission (2011) Directive of the European Parliament and of the Council on markets in financial instruments repealing Directive 2004/39/EC of the European Parliament and of the Council (Recast), 20 October 2011, Brussels. 
Conac, Pierre-Henri (2017) 'Algorithmic trading and high-frequency trading,' In: Busch, Danny and Guido Ferrarini (eds) Regulation of the EU Financial Markets: MiFIDII and MiFIR, Oxford: Oxford University Press, 469-485.

ESMA (2014) 'Economic report on high-frequency trading activity in EU equity markets,' Number 1, 2014.

Ferrarini, Guido and Niamh Moloney (2012) 'Reshaping order execution in the EU and the role of interest groups: from MiFID I to MiFID II,' European Business Organization Law Review, 13, 557-597.

Financial Times (2013) 'Italy introduces tax on high-speed trade and equity derivatives,' 1 September.

Financial Times (2018) 'Goldman to treble Swedish office as post-Mifid equities hub,' 4 May.

Gomber, Peter and Frank Nassauer (2014) 'Neuordnung der Finanzmärkte in Europa durch MiFID II/MiFIR,' White Paper Series No. 20.

Kennedy, Steven (2017) 'Making history,' ISDA Quarterly, 3:3, 3.

Kindermann, Jochen, Fox Darren, Colston Nicholas, Stalin Charlotte and Penny Miller (2016) 'Algo and high frequency trading under MiFID2 - a few more pieces in the puzzle,' Simmons \& Simmons elexica. http:/www.elexica.com/en/legal-topics/ asset-management/25-algo-and-high-frequency-trading-under-mifid2, accessed 11 March 2019.

Kingdon, John W. [1984] (2003) Agendas, Alternatives, and Public Policies, 2nd edition, New York: Longman.

Krotz, Ulrich and Joachim Schild (2013) Shaping Europe: France, Germany, and Embedded Bilateralism from the Elysée Treaty to twenty-First Century Politics, Oxford: Oxford University Press.

Lehner, Thomas and Fabio Wasserfallen (2019) 'Political conflict in the reform of the eurozone,' European Union Politics, 20:1, 45-64.

Meissner, Katharina L. and Lachlan McKenzie (2018) 'The paradox of human rights conditionality in EU trade policy: when strategic interests drive policy outcomes,' Journal of European Public Policy, 26:9, 1273-1291. DOI: $10.1080 / 13501763.2018 .1526203$.

Moloney, Niamh (2012) 'MiFID II: reshaping the perimeter of EU trading market regulation,' Guest Editorial, Law and Financial Markets Review, 6:5, 327-330.

Newman, Abraham and Elliot Posner (2016) 'Transnational feedback, soft law, and preferences in global financial regulation,' Review of International Political Economy, 23:1, 123-152.

NRC Handelsblad (2018) Nog geen uitzondering voor flitshandelaren, 7 March.

Quaglia, Lucia (2012) "The "old" and "new" politics of financial services regulation in the European Union,' New Political Economy, 17:4, 515-535.

Schoeller, Magnus G. (2018) 'The rise and fall of Merkozy: Franco-German bilateralism as a negotiation strategy in eurozone crisis management,' Journal of Common Market Studies, 56:5, 1019-1035.

Sheridan, Iain (2017) 'MiFID II in the context of financial technology and regulatory technology,' Capital Markets Law Journal, 12:4, 417-427.

Spendzharova, Aneta (2017) 'Becoming a powerful regulator: the European Securities and Markets Authority (ESMA) in European financial sector governance,' TARN Working Paper 8/2017.

The Economist (2013) 'Electronic trading. Dutch fleet. The home of the world's first stock exchange is now a high-frequency heartland,' 20 April. 
Wasserfallen, Fabio and Thomas Lehner (2017) 'Mapping contestation on economic and fiscal integration: evidence from new data,' EMU Choices Working Paper, University of Salzburg, 23.

\section{INTERVIEWS}

Interview 1 (2019) European Parliament, senior official, 1 July, Brussels, Belgium.

Interview 2 (2019) Dutch Authority for the Financial Markets (AFM), official, 3 July, The Hague, the Netherlands.

Interview 3 (2019) Commissione Nazionale per la Societá e la Borsa (CONSOB Italian financial markets authority), official, 2 July, Rome, Italy. 